\title{
Mid-luteal angiogenesis and function in the primate is dependent on vascular endothelial growth factor
}

\author{
S E Dickson, R Bicknell ${ }^{1}$ and $\mathbf{H}$ M Fraser
}

MRC Human Reproductive Sciences Unit, Centre for Reproductive Biology, 37 Chalmers Street, Edinburgh EH3 9ET, UK

${ }^{2}$ Molecular Angiogenesis Laboratories, Imperial Cancer Research Fund, Institute of Molecular Medicine, John Radcliffe Hospital, Oxford OX3 9DS, UK

(Requests for offprints should be addressed to H M Fraser, MRC Human Reproductive Sciences Unit, Centre for Reproductive Biology, 37 Chalmers Street, Edinburgh EH3 9ET, UK; E-mail: h.fraser@hrsu.mrc.ac.uk)

\begin{abstract}
Vascular endothelial growth factor (VEGF) is essential for the angiogenesis required for the formation of the corpus luteum; however, its role in ongoing luteal angiogenesis and in the maintenance of the established vascular network is unknown. The aim of this study was to determine whether VEGF inhibition could intervene in ongoing luteal angiogenesis using immunoneutralisation of VEGF starting in the mid-luteal phase. In addition, the effects on endothelial cell survival and the recruitment of periendothelial support cells were examined. Treatment with a monoclonal antibody to VEGF, or mouse gamma globulin for control animals, commenced on day 7 after ovulation and continued for 3 days. Bromodeoxyuridine (BrdU), used to label proliferating cells to obtain a proliferation index, was administered one hour before collecting ovaries from control and treated animals. Ovar-
\end{abstract}

ian sections were stained using antibodies to BrdU, the endothelial cell marker, CD31, the pericyte marker, alpha-smooth muscle actin, and $3^{\prime}$ end DNA fragments as a marker for apoptosis. VEGF immunoneutralisation significantly suppressed endothelial cell proliferation and the area occupied by endothelial cells while increasing pericyte coverage and the incidence of endothelial cell apoptosis. Luteal function was markedly compromised by anti-VEGF treatment as judged by a $50 \%$ reduction in plasma progesterone concentration. It is concluded that ongoing angiogenesis in the mid-luteal phase is primarily driven by VEGF, and that a proportion of endothelial cells of the mid-luteal phase vasculature are dependent on VEGF support.

Journal of Endocrinology (2001) 168, 409-416

\section{Introduction}

Formation of the primate corpus luteum (CL) is accompanied by prolific angiogenesis in the early luteal phase, and throughout the life span of the CL angiogenesis continues at a lower rate until the late luteal phase when endothelial cell proliferation decreases further (JablonkaShariff et al. 1993, Rodger et al. 1997, Dickson \& Fraser 2000). The angiogenic process is regulated by a number of growth factors, degradation of the extracellular matrix and cell-cell interactions. One growth factor primarily involved is vascular endothelial growth factor (VEGF).

The importance of VEGF in the onset of luteal angiogenesis has been demonstrated by specific VEGF neutralisation in the rat (Ferrara et al. 1998) and the marmoset monkey (Fraser et al. 2000) which resulted in suppression of endothelial cell proliferation, restricted development of the microvascular tree and decreased progesterone production. These studies have solely addressed prevention of angiogenesis by targeting the early luteal phase just before the onset of angiogenesis (see Fig. 1) (Dickson \& Fraser 2000, Fraser et al. 2000). Surprisingly, while immunone- utralisation of VEGF for the first 3 days of the luteal phase markedly suppressed angiogenesis, extending treatment to 10 days post ovulation failed to affect mid-luteal cell proliferation (Fraser et al. 2000). It is possible that endothelial cell proliferation was unaffected at this stage as a result of (1) induction of a compensatory effect from other growth factors after chronic inhibition of VEGF, (2) an immune response against the mouse monoclonal antibody or (3) the possibility that VEGF was not involved in stimulating endothelial cell proliferation during this period. In the light of this observation the current study investigated the role of VEGF specifically during the mid-luteal phase to determine whether VEGF inhibition would intervene in ongoing luteal angiogenesis.

First, using quantitative immunocytochemistry we established that VEGF was present in high amounts during the mid-luteal phase. We then investigated whether it was possible to intervene in the already established angiogenic process by administering anti-VEGF treatment for 3 days in the mid-luteal phase and examining the effects on angiogenesis and luteal function. 
Previous studies on the effects of withdrawal of VEGF in other angiogenic-dependent systems report the requirement of VEGF for the survival of immature endothelial cells. For example, in human prostate cancer the loss of VEGF as a result of androgen ablation therapy leads to selective apoptosis of endothelial cells in vessels devoid of periendothelial support cells (Benjamin et al. 1999). To investigate whether endothelial cells of the primate CL may be susceptible to withdrawal of VEGF, we determined the incidence of apoptosis after anti-VEGF treatment. Finally, to assess the relationship of periendothelial support cells to endothelial cell survival, the area of pericyte coverage in control CL and after anti-VEGF treatment was quantified.

\section{Materials and Methods}

\section{Animals and treatments}

Marmoset monkeys (Calithrix jacchus) were housed as described previously (Fraser et al. 1999a) and procedures were carried out in accordance with the Animals (Scientific Procedures) Act 1986. Blood samples were collected by femoral venepuncture three times per week without anaesthesia. Ovulatory cycles were monitored by radioimmunoassay of plasma progesterone as previously described (Smith et al. 1990). The day of ovulation (day 0 of the luteal phase) was taken as the day on which progesterone concentration rose above $30 \mathrm{nmol} / 1$ when followed by a sustained increase, characteristic of the luteal phase.

Ovaries collected from animals in the early (luteal days 2-4), mid- (days 8-10) and late (days 16-20) luteal phase of the ovulatory cycle $(n=4-5$ animals per group) for previous studies (Fraser et al. 1999a,b, Dickson \& Fraser 2000) were used for immunocytochemical localisation and quantification of VEGF protein.

The mid-luteal phase was targeted for anti-VEGF treatment to determine whether luteal angiogenesis could be prevented at the stage when high levels of VEGF are present, as seen by VEGF immunolocalisation throughout the luteal phase of the marmoset ovulatory cycle.

Animals were given $1 \mu \mathrm{g}$ prostaglandin $\mathrm{F}_{2 \alpha}$ analogue (Planate; Coopers Animal Health Ltd, Crewe, Cheshire, UK) i.m. in the mid- to late luteal phase of the pretreatment cycle to induce luteolysis and to synchronise subsequent ovulation which was presumed to occur 10 days after prostaglandin treatment (luteal day 0) (Fig. 1) (Summers et al. 1985). Blood samples were collected every second day, then daily from the first day of treatment. The properties of the VEGF monoclonal antibody have been described previously (Fraser et al. 2000). Four animals were subsequently treated with 2 mg VEGF monoclonal antibody on luteal day 7 and $1 \mathrm{mg}$ on luteal days 8 and 9, and four control animals were given equivalent doses of mouse gamma globulin (Fig. 1). Ovaries were collected on day 10 as previously described by Fraser et al. (1998), $1 \mathrm{~h}$

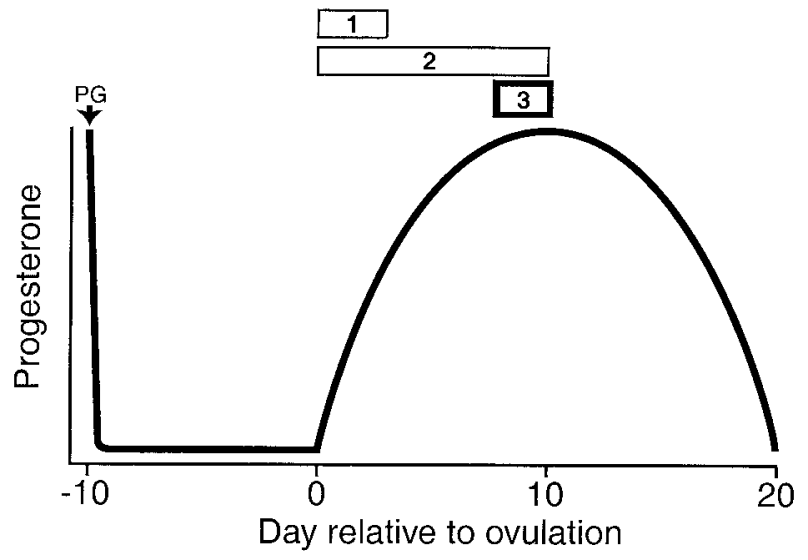

Figure 1 Schematic diagram showing the different treatment regimes (1,2 and 3 ) with VEGF monoclonal antibody designed to determine whether inhibition of angiogenic factors can prevent angiogenesis (regimes 1 and 2) or intervene once the process is underway (regime 3). The approach used in the current study was to intervene in the already established angiogenic process by administering a 3-day treatment with VEGF monoclonal antibody in the mid-luteal phase according to regime 3. PG, prostaglandin $F_{2 \alpha}$ analogue.

after administration of $20 \mathrm{mg}$ bromodeoxyuridine (BrdU; Boehringer Mannheim, Lewes, East Sussex, UK) dissolved in $500 \mu \mathrm{l}$ physiological saline, to label proliferating cells in the $\mathrm{S}$ phase of the cell cycle. Ovaries were fixed immediately in $4 \%$ paraformaldehyde in $0.01 \mathrm{M}$ PBS (phosphate-buffered saline, $\mathrm{pH} 7 \cdot 4$, containing $2.7 \mathrm{mM}$ $\mathrm{KCl}, 0 \cdot 137 \mathrm{M} \mathrm{NaCl}$ ) for paraffin-embedding.

\section{Immunocytochemistry}

Paraffin-embedded ovarian sections $(5 \mu \mathrm{m})$ were mounted onto TESPA- (Sigma, Poole, Dorset, UK) coated glass slides and dried at $50{ }^{\circ} \mathrm{C}$ overnight. To carry out immunocytochemistry for VEGF, sections were dewaxed in Histoclear (National Diagnostics, Aylesbury, Bucks, UK), rehydrated in descending concentrations of industrial methylated spirits and washed in distilled water. VEGF antigen was retrieved by pressure cooking slides on full power in $3 \mathrm{M}$ glycine, $0 \cdot 1 \%$ EDTA buffer, $\mathrm{pH} 3 \cdot 5$, for $5 \mathrm{~min}$. The slides remained in hot buffer for a further $20 \mathrm{~min}$ and were washed in TBS (0.05 M Tris-buffered saline, $\mathrm{pH} 7 \cdot 4$, containing $50 \mathrm{mM}$ Tris- $\mathrm{HCl}, 150 \mathrm{mM}$ $\mathrm{NaCl}$ ). Endogenous peroxidase activity was quenched with a 30-min incubation in 3\% hydrogen peroxide in methanol at room temperature. The following procedures, with the exception of immunostaining development, were carried out in Sequenza racks (Shandon Scientific Ltd, Runcorn, Cheshire, UK). To block endogenous biotin, sections were incubated in avidin (Vector Laboratories, Burlingame, CA, USA) at a concentration of 8 drops $/ \mathrm{ml}$ normal swine serum (NSS, 1:5 dilution in TBS $+0 \cdot 25 \mathrm{~g}$ bovine serum albumin), followed by a $20-$ min incubation 
in biotin (Vector Laboratories) in TBS (8 drops $/ \mathrm{ml}$ ). Rabbit polyclonal VEGF antibody $(2 \mu \mathrm{g} / \mathrm{ml}$ pre-diluted in NSS, Santa Cruz Biotechnology, Santa Cruz, CA, USA) was added and sections were incubated at $4{ }^{\circ} \mathrm{C}$ overnight. Negative controls were incubated in primary antibody pre-absorbed with VEGF peptide in 1:5 ratio of VEGF antibody:blocking peptide (Santa Cruz). Immunolocalisation was undertaken using the rabbit EnVision kit (Dako Ltd, Cambridge, Cambs, UK) according to the guidelines of the manufacturer.

BrdU immunocytochemistry was carried out using a monoclonal antibody (Boehringer Mannheim) as previously described (Fraser et al. 2000). Immunocytochemistry for the endothelial cell marker, CD31 (Dako Ltd), and the pericyte marker, alpha-smooth muscle actin (SMA; Dako Ltd), were performed using monoclonal antibodies $(20.5 \mu \mathrm{g} / \mathrm{ml}$ in TBS and $4.3 \mu \mathrm{g} / \mathrm{ml}$ in TBS respectively) and the same method as for BrdU immunostaining.

Apoptosis was detected by $3^{\prime}$ end labelling as previously described in the marmoset CL (Young et al. 1997), with modifications according to Sharpe et al. (1998). An additional proteinase $\mathrm{K}$ digestion step was performed after dewaxing and rehydrating the sections. Slides were incubated for $6 \mathrm{~min}$ at room temperature in $20 \mu \mathrm{g} / \mathrm{ml}$ proteinase $\mathrm{K}$ in buffer containing 0.05 M Tris, $\mathrm{pH}$ 8, 0.05 M EDTA, $\mathrm{pH} 8$, in distilled $\mathrm{H}_{2} \mathrm{O}$. After blocking of endogenous peroxidase activity, it was necessary to block endogenous biotin using the avidin-biotin block in PBS as above.

\section{Analysis}

A BrdU proliferation index (PI) was obtained as previously described (Dickson \& Fraser 2000). Endothelial cell and pericyte areas were quantified in at least 6 randomly chosen areas of $5.3 \times 10^{4} \mu \mathrm{m}^{2}$ (approximately two thirds of each CL) as described by Fraser et al. (2000) for the endothelial cell marker, Factor VIII. The area of VEGF immunostaining was measured using Photoshop version $5 \cdot 0$ according to the method of Otani et al. (1999). Statistical analysis of VEGF immunostaining throughout
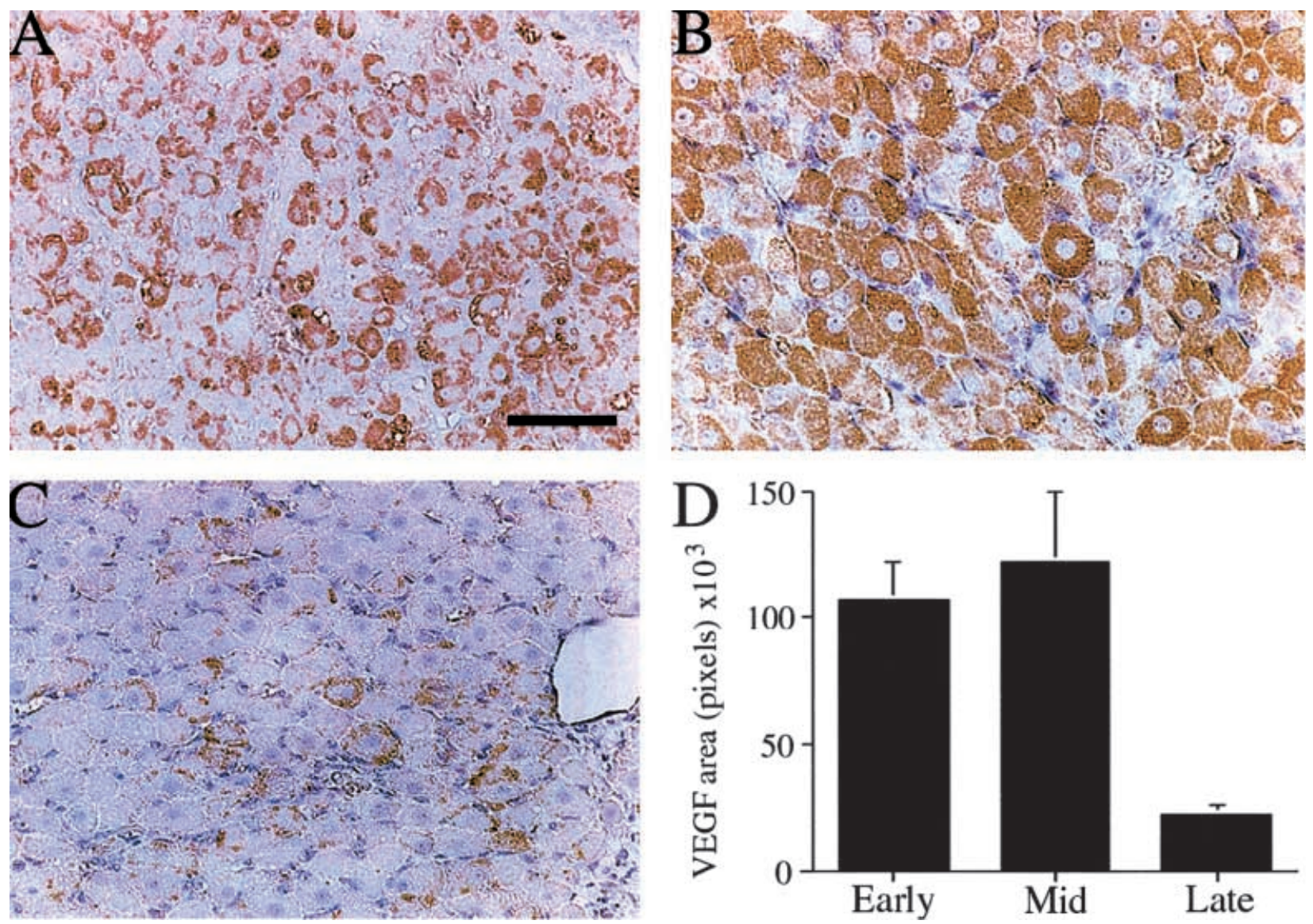

Figure 2 Photomicrographs of marmoset corpora lutea showing VEGF localisation (brown staining cytoplasm) in (A) an early luteal phase corpus luteum, (B) a mid-luteal phase corpus luteum and (C) a late luteal phase corpus luteum. Bar represents $50 \mu \mathrm{m}$. (D) Quantification of the area of VEGF immunostaining in the marmoset corpus luteum throughout the luteal phase of the ovulatory cycle. Early and mid-luteal values are significantly higher $(P=0.04$ and $P=0.02$ respectively) than the late luteal value. Data are means \pm S.E.M. 
the ovulatory cycle was carried out using a factorial one-way analysis of variance (ANOVA) with Fisher's PLSD (protected least significant difference) post-hoc test at $5 \%$ significance. The effects of anti-VEGF treatment on PI, endothelial cell and pericyte areas, apoptotic index and VEGF immunostaining, as compared with controls, were determined using separate two-tailed, unpaired $t$-tests, with $95 \%$ confidence intervals. Serum progesterone concentrations were analysed using a repeated measures ANOVA with Fisher's PLSD post-hoc test at 5\% significance. All tests were performed using Statview version $4 \cdot 0$.

\section{Results}

\section{VEGF immunocytochemistry throughout the cycle}

Figure 2 illustrates the localisation and quantification of VEGF immunostaining in the CL during the early, midand late luteal phase. Early luteal sections show intense, punctate VEGF staining in the cytoplasm of lutein cells (Fig. 2A) which becomes more uniform and widespread in the mid-luteal phase CL (Fig. 2B). Staining was absent from recognisable endothelial cells. In the late luteal phase CL, VEGF staining was markedly reduced (Fig. 2C). Quantification confirmed a high area of staining in the early and mid-luteal phase which declined markedly in the late luteal phase CL, as compared with early and midluteal levels ( $P=0.04$ and $P=0.02$ respectively) (Fig. 2D).

\section{BrdU, CD31 and SMA immunocytochemistry}

Figure 3 shows comparisons of BrdU incorporation, CD31 and SMA immunostaining, and their quantification in mid-luteal control and anti-VEGF-treated CL. Moderate $\mathrm{BrdU}$ incorporation into endothelial cells was observed in control CL (Fig. 3A) but this was significantly lowered by anti-VEGF treatment (Fig. 3B). This was confirmed by comparing the PI from control and treated groups $(P<0 \cdot 01)$ (Fig. 3C). In the control CL, CD31 immunostaining confirmed the establishment of the microvascular tree demonstrated by numerous blood vessels and capillary endothelial cells being observed in association with each lutein cell (Fig. 3D). In the treated animals, the number of capillaries appeared reduced (Fig. 3E) and quantitative analysis revealed a significant $(P=0 \cdot 02)$ decrease in endothelial cell area after treatment (Fig. 3F). The converse was apparent for SMA immunostaining. In control sections, pericytes were mostly found aggregated in rings surrounding luminal vessels (Fig. 3G), whereas after anti-VEGF treatment single immunopositive cells were also found distributed through the CL (Fig. $3 \mathrm{H}$ ). Quantification of pericyte area in control sections and after anti-VEGF treatment is shown in Fig. 3I $(P<0 \cdot 01)$.

\section{Apoptotic cell death}

Figure 4 demonstrates $3^{\prime}$ end labelling in mid-luteal control and treated sections. One positive apoptotic endo- thelial cell associated with a blood vessel can be seen in Fig. 4A. The incidence of apoptotic nuclei increased with anti-VEGF treatment as seen in Fig. 4B which shows two positive nuclei probably of endothelial cell origin. Positive apoptotic nuclei remained sparsely distributed, even though anti-VEGF treatment significantly $(P=0.03)$ increased the occurrence of apoptosis (Fig. 4C). The incidence of apoptotic cells was measured per CL section as the size of the control and treated CL did not differ significantly. The regular shape of the steroidogenic lutein cells in control CL was retained in the treated CL.

\section{Plasma progesterone concentration}

A sustained elevation of plasma progesterone was observed prior to treatment in all animals. After administration of anti-VEGF treatment starting on luteal day 7 there was a marked reduction in plasma progesterone concentrations which had fallen by over $50 \%$ by day 10 (Fig. 5$)(P=0 \cdot 01)$.

\section{Discussion}

This study has demonstrated for the first time that VEGF is essential for luteal angiogenesis even when the process is already established. Furthermore, inhibition of VEGF at this time suppresses the function of the CL. We have also demonstrated that VEGF appears to have a role in maintenance of the vascular network in the mid-luteal CL as shown by an increase in $3^{\prime}$ end labelling after VEGF withdrawal.

Our findings also show that the expression of VEGF is high not only in the early luteal period of intense angiogenesis, but also in the less prolific mid-luteal phase CL, and is only down regulated after initiation of luteolysis. This agrees with VEGF measurements throughout the life span of the CL in the bovine (Goede et al. 1998) and the human CL (Otani et al. 1999). In the present study, the deleterious effect of acute removal of VEGF on mid-luteal angiogenesis shows that ongoing mid-luteal angiogenesis is driven primarily by this growth factor. This indicates that the failure to observe an effect on mid-luteal endothelial cell proliferation after chronic withdrawal of VEGF treatment from the time of ovulation (Fraser et al. 2000) is a consequence of induction of other growth factors to compensate for the inhibition of VEGF or inactivation of the neutralising antibody by an immune response.

The high mid-luteal expression of VEGF could also reflect some of the non-angiogenic functions of VEGF, such as the regulation of vascular permeability or the mediation of endothelial cell survival as suggested by Goede et al. (1998). By the mid-luteal phase, the vasculature is becoming highly developed and progesterone is being maximally secreted. If the effect of anti-VEGF was solely to suppress angiogenesis it might be anticipated that progesterone would be maintained at pretreatment levels, 

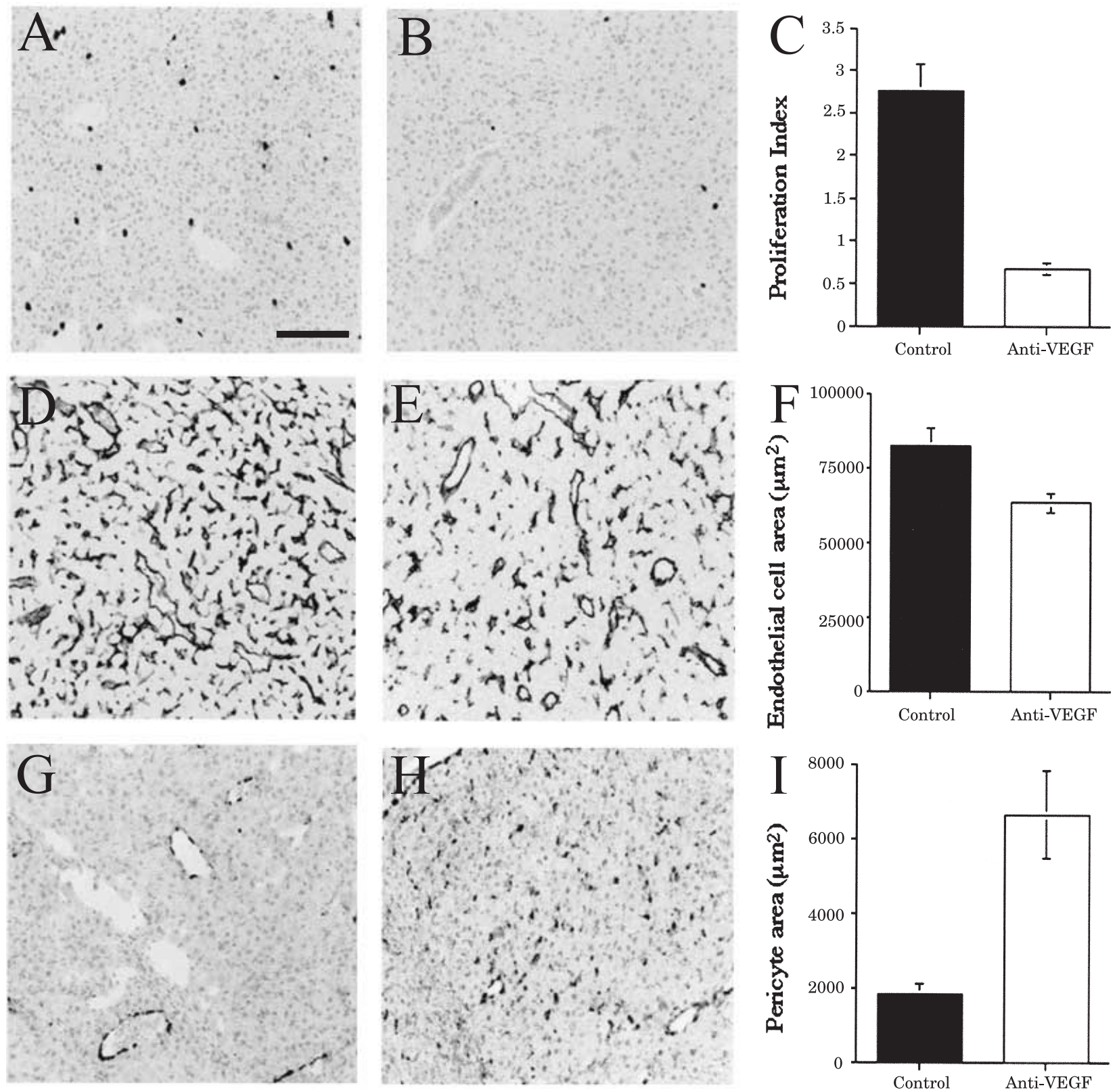

Figure 3 Low power photomicrographs of marmoset corpora lutea showing the general distribution of endothelial cell BrdU incorporation (dark-staining nuclei) in a control section $(\mathrm{A})$ and its reduced incorporation after anti-VEGF treatment (B). (C) The proliferation index in corpora lutea from mid-luteal phase controls (solid bar) and anti-VEGF-treated (open bar) marmoset corpora lutea. Values from treated animals were significantly lower $(P<0 \cdot 01)$ than those from controls. (D) CD31 localisation (dark staining) in the endothelial cells of the vascular network in a mid-luteal phase control corpus luteum. (E) Reduced CD31 staining after anti-VEGF treatment. (F) Quantification of CD31 immunostaining in control (solid bar) and anti-VEGF-treated (open bar) marmoset corpora lutea. Values from treated animals were significantly lower $(P=0.02)$ than those from controls. (G) Smooth muscle actin localisation in pericytes in a control section, and $(\mathrm{H})$ increased smooth muscle actin immunostaining after anti-VEGF treatment. Note that the dark stained cells in control and treated sections are characteristic of perivascular cells, based on the small size and elongated shape; none appears to be of lutein cell origin. (I) Quantification of alpha-smooth muscle staining in control (solid bar) and anti-VEGF-treated (open bar); values from treated animals were significantly $(P=<0 \cdot 01)$ higher than those from controls. Data are means \pm S.E.M. Bar represents $100 \mu \mathrm{m}$. 

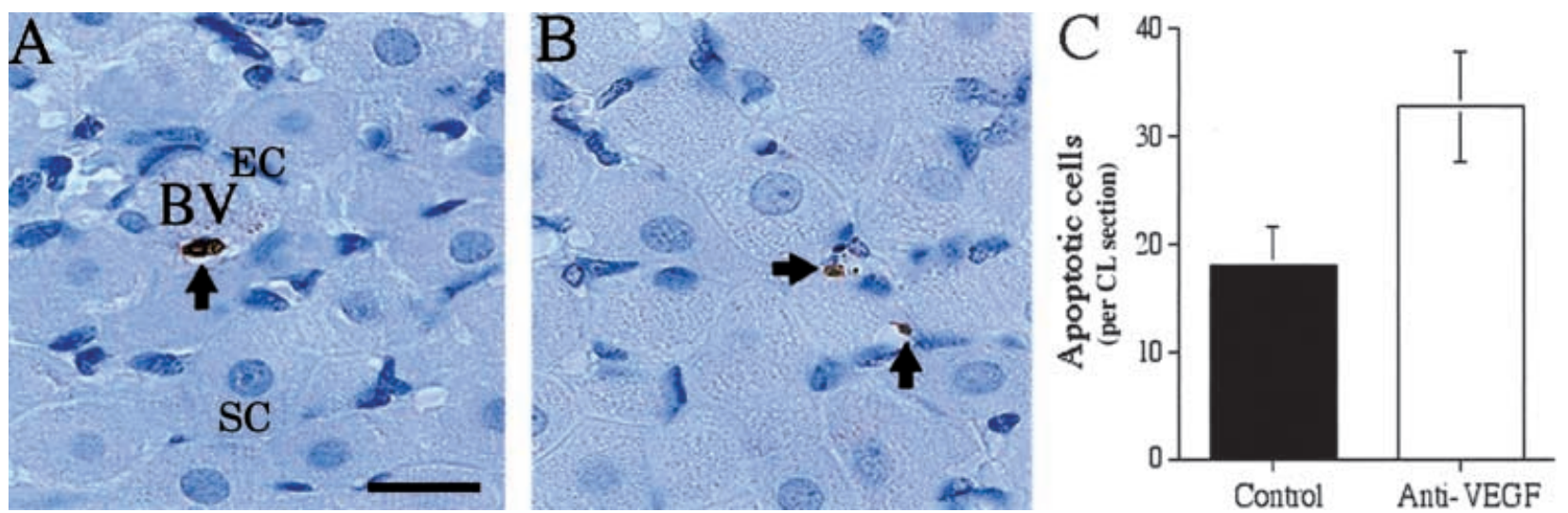

Figure 4 High power photomicrographs of $3^{\prime}$ end labelled apoptotic cells (brown staining) in (A) a mid-luteal phase control marmoset corpus luteum and (B) after anti-VEGF treatment. Note the presence of endothelial cells (EC) surrounding a blood vessel (BV) in the control section, and smaller dark haematoxylin-stained nuclei representing endothelial cells and periendothelial support cells in both control and treated CL. Arrows point to positive apoptotic nuclei assumed to be endothelial cells by their small, elongated form. The morphology of steroidogenic cells (SC) appears unaffected by treatment. (C) Quantification of positive cells in control (solid bar) and treated sections (open bar) shows increased presence of positive nuclei in anti-VEGF-treated sections. Note that values are per corpus luteum section so the incidence of apoptosis even after treatment is very low. Data are means \pm S.E.M. Bar represents $20 \mu \mathrm{m}$.

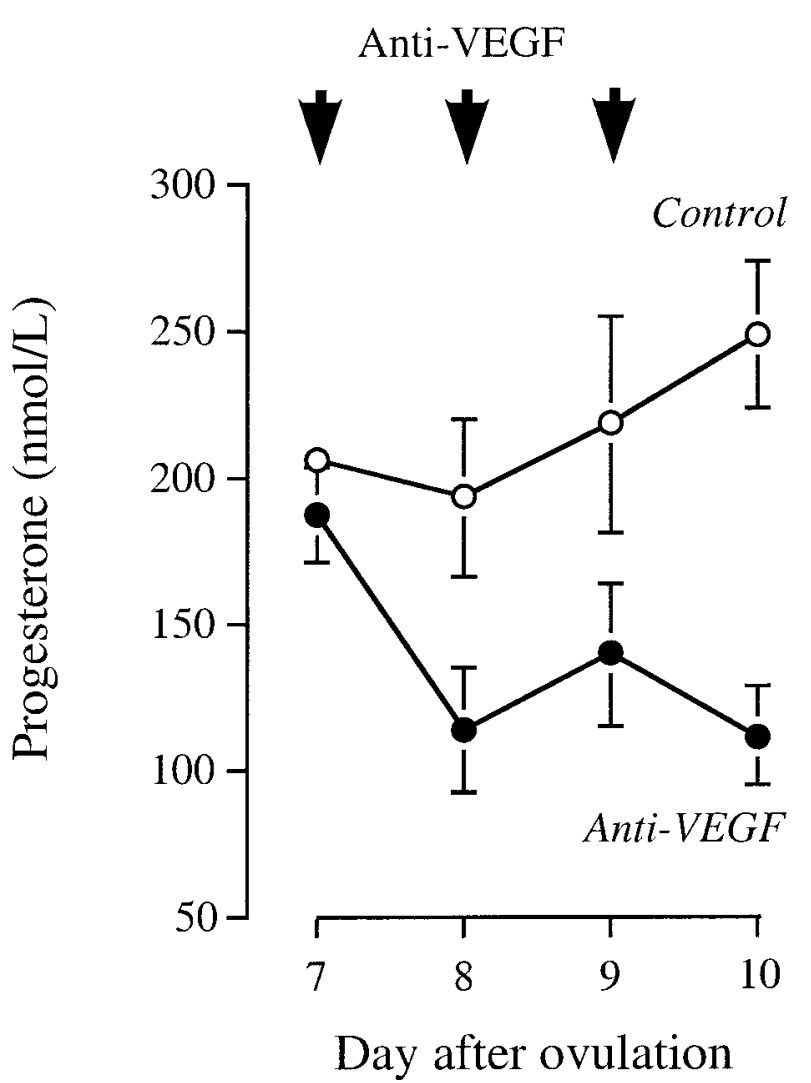

Figure 5 Plasma progesterone concentrations in control $(O)$ and anti-VEGF-treated (0) marmosets. Treatment started on day 7 after ovulation and is associated with a significant suppression $(P=0 \cdot 01)$. Data are means \pm S.E.M. at least during the first 1-2 days of treatment. The rapid decline in plasma progesterone concentration seen on the first day of this acute mid-luteal phase anti-VEGF treatment, indicates that in addition to the regulation of ongoing mid-luteal angiogenesis, VEGF also modulates vascular permeability in the CL. An effect on CL vascular permeability could deprive the lutein cells of both the necessary precursors for progesterone production and the efficient release of their products into the bloodstream, which would result in marked reductions in plasma progesterone values.

After anti-VEGF treatment, morphological changes in lutein steroidogenic cells were not apparent. This contrasts with observations on the characteristic effects of withdrawal of the trophic factor, luteinising hormone (LH), which have been described recently (Fraser et al. 1999b, Dickson \& Fraser 2000), suggesting that anti-VEGF treatment does not markedly interfere with pituitary $\mathrm{LH}$ secretion.

In this study, we have also observed an increase in pericyte coverage as a result of VEGF withdrawal. Pericytes are believed to be involved in the remodelling process which occurs during blood vessel maturation (reviewed by Darland \& D'Amore 1999), a process also thought to take place in the CL (Tsukada et al. 1996, Goede et al. 1998). Benjamin et al. (1999) demonstrated that in both xenografted tumour and primary human tumours, VEGF withdrawal resulted in specific obliteration of immature vessels and that in human prostate cancer loss of VEGF led to selective apoptosis of endothelial cells devoid of periendothelial cells. Mature vessels with associated pericytes are believed to be VEGF 
independent (Benjamin et al. 1998). It is possible that, in the current study, the increase in apparent apoptosis in endothelial cells after anti-VEGF treatment is a consequence of a lack of VEGF support to susceptible, immature vessels with no associated pericytes. It could follow, therefore, that endothelial cells of more mature vessels with associated pericytes would be VEGF independent and not susceptible to anti-VEGF treatment. Our finding that mid-luteal VEGF withdrawal led to an increase in endothelial cell apoptosis, the occurrence of which was rare, in the presence of extended pericyte coverage suggests that it is the endothelial cells associated with the few remaining immature capillaries which were susceptible to loss of VEGF support. This, in turn, indicates that the reduction in endothelial cell area after anti-VEGF treatment may be a consequence not only of a decreased angiogenic rate, but also of increased endothelial cell death.

Factors involved in the recruitment of pericytes include platelet-derived growth factor-B (reviewed in Darland \& D'Amore 1999) and angiopoietin-1 (Davis et al. 1996, Maisonpierre et al. 1997, Koblizek et al. 1998), while transforming growth factor $\beta$ is thought to regulate pericyte differentiation (Hirschi et al. 1999). It remains to be determined whether factors such as angiopoietin-1 may be activated after VEGF inhibition to act as a survival mechanism to 'rescue' existing vessels from the absence of the immature endothelial cell survival factor, VEGF.

In conclusion, this study demonstrates that VEGF is a primary factor controlling angiogenesis and luteal function in the mid-luteal phase. The rapid decline in plasma progesterone after VEGF inhibition suggests that another function of VEGF at this stage may be in the maintenance of vascular permeability. In addition, the increase in endothelial cell apoptosis indicates a role for VEGF in the survival of a proportion of endothelial cells, perhaps those without associated periendothelial support cells. However, further investigation into the role of VEGF in pericyte recruitment is required to further elucidate the processes of blood vessel maturation in the CL. Since the mid-luteal phase is a crucial period in the establishment of early pregnancy and a time at which survival of the luteal vasculature may be important in the 'rescue' of the CL, manipulation of VEGF may have clinical importance with respect to, on the one hand, treatment of early pregnancy loss, and, on the other hand, interruption of pregnancy.

\section{Acknowledgements}

We thank the staff of our primate unit for animal care, M Millar and S MacPherson for expert support with histology, and P Hartley and I Swanston for progesterone RIAs.

\section{References}

Benjamin LE, Hemo I \& Keshet E 1998 A plasticity window for blood vessels remodelling is defined by pericyte coverage of the preformed endothelial network and is regulated by PDGF-B and VEGF. Development 125 1591-1598.

Benjamin LE, Golojanin D, Itin A, Pode D \& Keshet E 1999 Selective ablation of immature blood vessels in established human tumors follows vascular endothelial growth factor withdrawal. Journal of Clinical Investigation 103 159-165.

Darland DC \& D'Amore PA 1999 Blood vessel maturation: vascular development comes of age. Journal of Clinical Investigation 103 157-158.

Davis S, Aldrich TH, Jones PF, Acheson A, Compton DL, Jain V, Ryan TE, Bruno J, Radziejewski C, Maisonpierre PC \& Yancopoulos GD 1996 Isolation of angiopoietin-1, a ligand for the TIE2 receptor, by secretion-trap expression cloning. Cell 87 1161-1169.

Dickson SE \& Fraser HM 2000 Inhibition of early luteal angiogenesis by gonadotropin-releasing hormone antagonist treatment in the primate. Journal of Clinical Endocrinology and Metabolism 85 2339-2344.

Ferrara N, Chen H, Davis-Smyth T, Hans-Peter G, Nguyen T-N, Peers D, Chisholm V, Hillan K \& Schwall R 1998 Vascular endothelial growth factor is essential for corpus luteum angiogenesis. Nature Medicine 4 336-340.

Fraser HM, Lunn SF, Kim H \& Erickson GF 1998 Insulin-like growth factor binding protein-3 (IGFBP-3) mRNA in the endothelial cells of the primate corpus luteum. Human Reproduction 13 2180-2185.

Fraser HM, Dickson SE, Morris KD, Erickson GF \& Lunn SF 1999a The effects of the angiogenesis inhibitor TNP-470 on luteal establishment and function in the primate. Human Reproduction $\mathbf{1 4}$ 2054-2060.

Fraser HM, Lunn SF, Harrison DJ \& Kerr JB 19996 Luteal regression in the primate: different forms of cell death during natural and gonadotropin-releasing hormone antagonist or prostaglandin analogue-induced luteolysis. Biology of Reproduction 61 1468-1479.

Fraser HM, Dickson SE, Lunn SF, Wulff C, Morris KD, Carroll V \& Bicknell R 2000 Suppression of luteal angiogenesis in the primate by neutralization of vascular endothelial growth factor. Endocrinology 141 995-1000.

Goede V, Schmidt T, Kimmina S, Kozian D \& Augustin HG 1998 Analysis of blood vessel maturation processes during cyclic ovarian angiogenesis. Laboratory Investigations 78 1385-1394.

Hirschi K, Rohovsky S, Beck L, Smith S \& D’Amore P 1999 Endothelial cells modulate the proliferation of mural-cell precursors via platelet-derived growth factor-BB and heterotypic cell contact. Circulation Research 84 298-305.

Jablonka-Shariff A, Grazul-Bilska AT, Redmer DA \& Reynolds LP 1993 Growth and cellular proliferation of ovine corpora lutea throughout the estrous cycle. Endocrinology 133 1871-1879.

Koblizek TI, Weiss C, Yancopoulos GD, Deutsch U \& Risau W 1998 Angiopoietin-1 induces sprouting angiogenesis in vitro. Current Biology 8 529-532.

Maisonpierre PC, Suri C, Jones PF, Bartunkova S, Wiegand SJ, Radziejewski C, Compton D, McLain J, Aldrich TH, Papadopoulos N, Daly TJ, Davis S, Sato TN \& Yancopoulos GD 1997 Angiopoietin2 , a natural antagonist for Tie2 that disrupts in vivo angiogenesis. Science $27755-60$

Otani N, Sawako M, Yamoto M, Shikone T, Otani H, Nishiyama R, Otani T \& Nakano R 1999 The vascular endothelial growth factor/fms-like tyrosine kinase system in human ovary during the menstrual cycle and early pregnancy. Journal of Clinical Endocrinology and Metabolism 84 3845-3851.

Rodger FE, Young FM, Fraser HM \& Illingworth PJ 1997 Endothelial cell proliferation follows the mid-cycle luteinizing hormone surge, but not human chorionic gonadotrophin rescue, in the human corpus luteum. Human Reproduction 12 1723-1729. 
Sharpe RM, Atanassova N, McKinnell C, Parte P, Turner KJ, Fisher JS, Kerr JB, Groome NP, MacPherson S, Millar MR \& Saunders PTK 1998 Abnormalities in functional development of the Sertoli cells in rats treated neonatally with diethylstilbestrol: a role for estrogens in Sertoli cell development. Biology of Reproduction 59 1084-1094.

Smith KB, Lunn SF \& Fraser HM 1990 Inhibin secretion during the ovulatory cycle and pregnancy in the common marmoset monkey. Journal of Endocrinology 126 489-495.

Summers PM, Wennink J \& Hodges JK 1985 Cloprostenol-induced luteolysis in the marmoset monkey (Callithrix jacchus). Journal of Reproduction and Fertility 73 133-138.
Tsukada K, Matsushima T \& Yamanaka N 1996 Neovascularization of the corpus luteum of rats during the estrous cycle. Pathology International 46 408-416.

Young FM, Illingworth PJ, Lunn SF, Harrison DJ \& Fraser HM 1997 Cell death during luteal regression in the marmoset monkey (Callithrix jacchus). Journal of Reproduction and Fertility 111 109-119.

Received 16 October 2000

Accepted 10 November 2000 